\title{
HELLRE EN NYBADAD SYNDARE ÄN TRENNE RÄTTFÄRDIGA MED FOTSVETT
}

\author{
Att återföra museernas föremål och vetande till verkligheten \\ via konsten
}

\begin{abstract}
"Då man filosoferar måste man stiga ner i det gamla kaoset, och känna sig väl till rätta där.»

"Mitt sätt att filosofera är fortfarande och ständigt åter på nytt för mig själv, och därför måste jag ofta upprepa mig. För en annan generation kommer det ha blivit kött och blod, och den kommer att finna upprepningarna långtråkiga. För mig är de nödvändiga»'
\end{abstract}

Eva Persson

En stor filosof fär hjälpa mig att be om ursäkt for att jag nu àter tar tillfalllet $i$ akt att upprepa vad jag redan skrivit och föreläst om så många gånger - alltför ensidigt dessutom, enligt en del kolleger.

Men for mig har det nästan förvandlats till ett filosofiskt problem. Denna gång formulerar jag frågan på följande sätt: Måste det uppstå en konflikt mellan det vetenskapliga innehållet och den konstnärliga formen i gestaltningen av museiutställningar? Jag kan som vanligt inte ge något definitivt svar, fortsätter bara att "filososofera». Fler medvetna utställningsexperiment i svenska museer skulle däremot kunna ge en hel del konkreta svar.

Det som för mig alltså tycks förbli konfliktartat, orsakar sällan problem för andra utställningsproducenter. De löser det alltmer uppmärksammade behovet att ge utställningarna en tilltalande yta och en spännande form genom att anlita arkitekter eller teaterscenografer.

Det finns flera skickliga och framför allt erfarna utställningsarkitekter och utställ- ningsscenografer, ${ }^{2}$ och jag frånkänner inte dem konstnärlighet. Men i arkitektens liksom scenografens hävdvunna yrkesroll ligger en stor grad av anpassning till ett innehåll som beställaren ansvarar för. Uppdraget är formgivning.

Om man däremot anlitar en konstnär skulptör, målare, fotograf, videoskapare eller annan självständig utforskare av bild- 
EVA PERSSON

94 mediet - blir ansvaret för innehållet mer komplicerat. En antikvarie eller intendent, som har vana att göra utställningar, vet att form och innehåll befinner sig i ständig växelverkan. Det accepteras om den innehållsliga tyngdpunkten förskjuts något på grund av en lyckad bildlösning. Men målsättningen är gemensamt underförstådd av beställaren och utställningsarkitekten, nämligen att innehållet som det presenteras av museets personal är överordnat formen, skall styra formen.

I samarbetet med en fri konstnär (jag vågar tala om sådana trots munsnörpningar från postmoderna teoretiker) behövs fortfarande en genom hela produktionen förd dialog mellan innehåll och form mellan beställare och gestaltare. ${ }^{3}$ Den i självutlevelse tränade konstnären visar sig då mer otålig, mer obelevad, mindre samarbetsvillig än formgivaren. Det är emellertid just därför som man väljer att samarbeta med en konstnär Man vet att konflikter är konstruktiva. Och som mediateoretikern McLuhan tror man, att «konsten som anti-miljö» är «ett medel att träna

Johan Tiréns känslosamt skildrade "Lappar tillvaratar skjutna renar" från 1892 bänger i konstavdelningen $i$ länsmuseet $i$ Östersund. Därifrän ser man ner på museets nyproducerade utställning om samekulturen $i$ länet. Tavlan är inte särskilt märklig, men ändå ett konstnärligt mästerverk i jämförelse med utställningen. Även innehållsmässigt är målningen intressantare än utställningen. Den ojämna striden mellan urbefolkning och nybyggare är den "undertext» som strukturevar målningen och ger den spänning. Denna historiskt avgörande konflikt undviks i utställningen, som blir bändelselös och inte kan forklara varfor sambället har förändrats. För den som vill förstå historien är det kanske ibland bättre att gå på konstmuseum än att se kulturhistoriska utställningar. iakttagelseförmågan och omdömet. ${ }^{4}$ Eller - för att åter citera Wittgenstein: «Människorna tror idag att vetenskapsmännen finns till för att undervisa dem, författare eller musiker, etc för att fröjda dem. Att

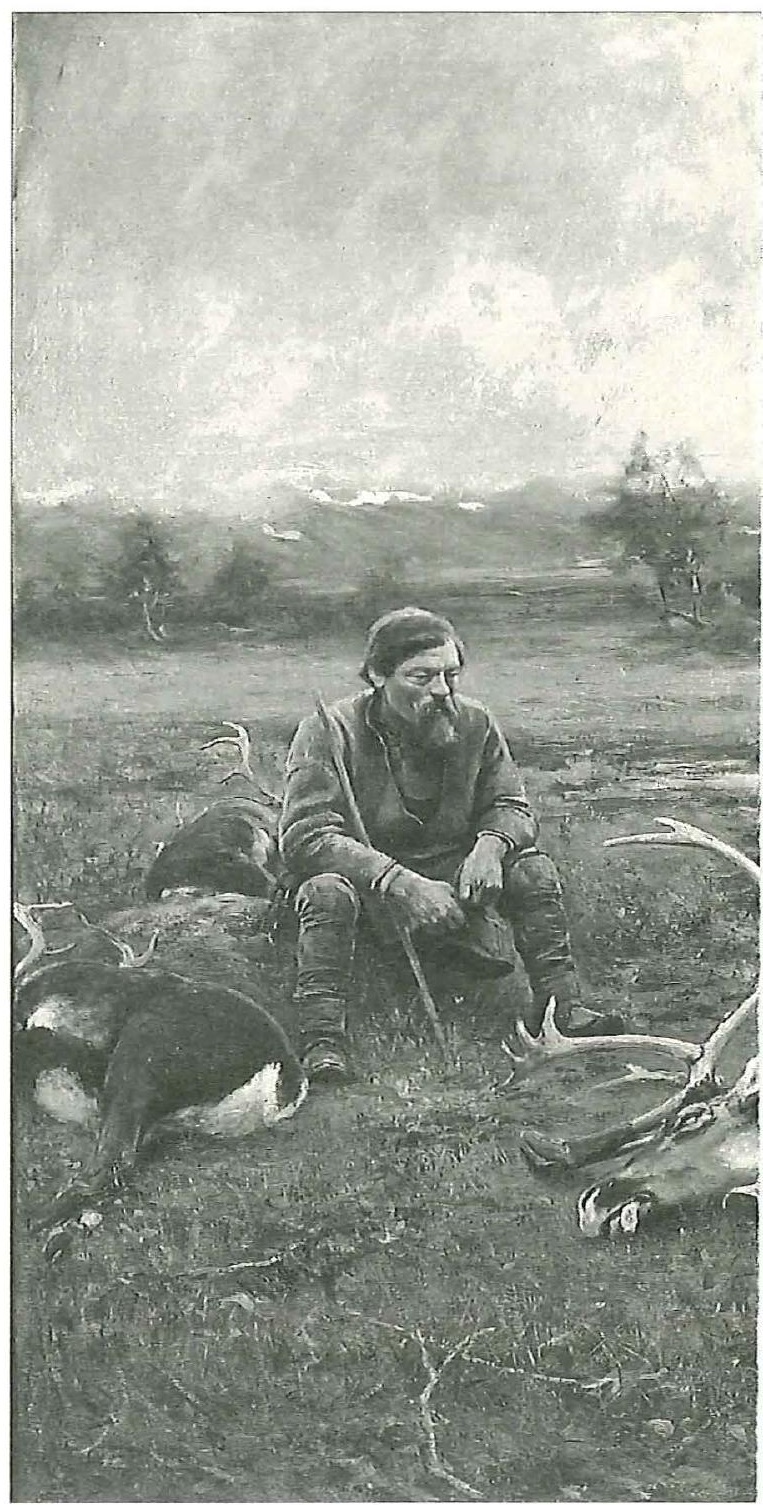


dessa senare kan ba något att lära dem faller dem inte in.. ${ }^{5}$

I den dynamiska dialog som (den rätt valde) bildkonstnären provocerar fram, uppstår snart «obehagliga» diskussioner om det manus som jag tillhandahåller. Vad är det egentligen för berättelse, som jag serverar museibesökarna? Och hur ser det, som på teaterspråk kallas undertext, ut? Alltså frågor om innehåll inte form,

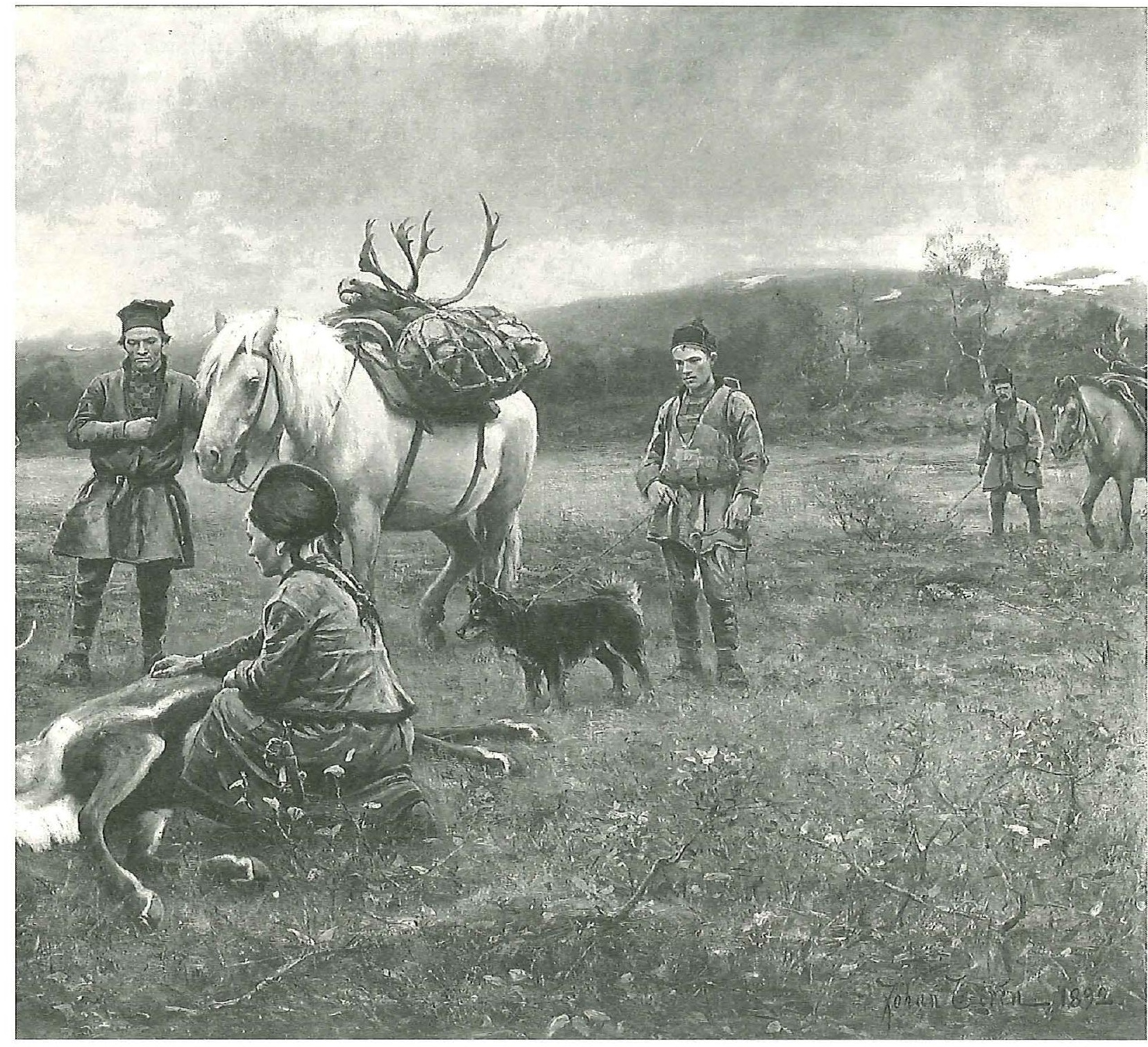


96 fast det är bildskaparen som väcker dem.

Feministetnologen Britta Lundgren önskar att museerna "vid sidan av starka och manbara manliga bönder och skogsarbetare eller dugliga arbetande och fruktsamma kvinnor» visade "magra och rädda bönder, opraktiska bönder, seniga tjuriga bönder, tjocka, lata och fryntliga, snåla och osympatiska bönder. Och vid sidan av de modiga och starka bondkvinnorna även kuvade, slarviga, tankspridda och lata kvinnor.» ${ }^{6}$

Ingen nu levande museiman eller kvinna kan motsätta sig detta - tvärtom skulle de flesta njuta av att få presentera sina samlingar ur sant mänskligt perspektiv. Men varför erbjuder museerna inte sina utställningsproducenter dessa möjligheter? Vem i beslutshierarkin motarbetar varje obehagligt "avslöjande» av den gamla bondeklassen? Vilka faror för museets akademiska anseende skulle lura bakom ett mer illusionsfritt berättande?

Jag tror inte att vare sig en museidirektör eller - ännu mindre - de forskningsansvariga vill hävda att forna tiders människor saknade motsägelsefulla personliga egenskaper. Att museiutställningarna är så förbannat lidelsefria, beror inte på chefers eller forskares förbud eller enskilda utställningsproducenters ovilja att se sanningen i vitögat. Förklaringar finns däremot i museernas bristande erfarenhet av att behandla konstnärliga processer och deras svårigheter att bryta med sin egen kulturs sega strukturer.

För att börja med det senare, de sega strukturerna - traditionernas tyranni, så handlar det om något enkelt: att uttrycka sig i utställningens form tar plats, kräver utrymme. Måste man spegla länets kulturhistoia från 10.000 år före Kristus till
1.900 år efter på tusen kvadratmeter så skapas en berättarteknik, med vars hjälp man inte kan fördjupa sig i den enskilda människans inre strider med sig själv (och förresten inte heller med sambon eller med samhället). Eftersom störtloppet upprepas även i nyuppförda museer ${ }^{7}$ utvecklas, tycks det, aldrig någon berättarteknik avsedd för skärskådandet av en enda dag (som i Ulysses) eller av en enskild individ (som Kristina från Duvemåla).

$V i$ reste till ett museum där man visade oss vår historia. Från orangutangerna till bäromnatten när vi älskade utan ansikten och därefter vände oss bort. Hela den utvecklingen. Trafiken, och tabletterna som brände vitt i mörkret ${ }^{8}$

I en dikt kan sammansatta upplevelser förmedlas på tio kvadratcentimeter. Utställningen är mer utrymmeskrävande. Skall poetens insikter om tillvarons absurditeter omvandlas till utställning behövs kvadratmetrar och åter kvadratmetrar. Var finns den golvytan om museerna fortsätter att sätta likhetstecken mellan basutställning och historisk översikt?

Museets utställningsverksamhet har alltid främst varit en funktion av dess samlingar, magasinens förlängda arm. Att mediet därför så småningom måste förtvina i narcissistisk självbespegling börjar man först nu inse.

I och med den radikalt nya mediesituationen i samhället vågar vissa museer säga, att föremålen måste frigöras ur det vetenskapliga insamlandets och magasinsordningens sekelgamla järngrepp. ${ }^{10}$ Så här beskriver Nordiska museets IT-chef Christer Larsson utmaningen: 
Museibesökarens sökande efter information eller upplevelse [...] följer knappast den traditionella museiindelningen, inte heller uppdelningen i museer och bibliotek, bildarkiv och ljudarkiv, etc. Dessa gränser är i viss mån konstlade och till stor del en följd av begränsningar i traditionell teknik. De nya IT-verktygen gör det möjligt att bryta gränserna och därmed betjäna en alltmer krävande museibesökare på ett mer ändamålsenligt sätt. Men de nya möjligheterna kräver nya synsätt."

Får vi, som länge nog talat om behovet av "nya synsätt», att "bryta gränser» och riva "konstlade murar» nu chansen att utveckla även utställningen för «en alltmer krävande museibesökare»? Eller kommer utställningen att bli ett bortglömt medium, när pengarna för den utåtriktade verksamheten går till det nyaste inom informationsteknologin? De ansvarsmuseer som leder IT-debatten känner inte något ansvar för utställningsmediets utveckling. De senaste årens produktioner i Nordiska museet och Riksmuseet är förstrött gjorda, de är stilistiskt omedvetna eller håller sig med plastens hjälp kvar i ett formspråk från det sena 1800-talet.

Elektroniken gör alltså, om man får tro IT-entusiasterna, museisamlingarna tillgängliga för var och en att forma sin egen populärvetenskapliga bildning och att efter eget skön fördjupa sina specialintressen. Den gammaldags folkbildningen sköter nu folk själva - med teknikens hjälp. Är inte detta ett gyllene tillfälle för utställningen att definiera sig på nytt, bli självmedveten och våga se sig som en konstform?

Utställningen som konstform - det uttrycket tror jag många museimänniskor värjer sig mot. Hur skall man övertyga chefer, antikvarier, konservatorer, vakt- mästare och tekniker att deras föremål hämtade ur nu försvunna verkligheter kan återföras till verkligheten igen - men att det är en konst? Hur skall man bevisa att den nya, utställda verkligheten blir trovärdig genom lögnen - bara man överlåter ljugandet till människor med stor konstnärlig kraft och erfarenhet?

På våra museer finns hemligt vetande, dolda kunskaper, som umgänget med föremål och fotografier, ytterligt privata brevsamlingar och personligt laddade dokument givit museimänniskorna. I förhållande till sitt vetande och den glöd med vilken de muntligen framställer det, är museifolket i allmänhet oerhört dåligt på att göra utställningar.

Vem skall kunna tolka och strukturera deras berättelse om föremålen, så att dessa behåller sina hemskheter och sin godhet när de ligger där i montern - övergivna av sina älskare och mentorer, antikvarierna och intendenterna?

«Man vill ju bli berörd, förförd, äcklad, upprörd när man går på museum», säger Sveriges kulturminister hösten 1995. ${ }^{12}$ Kanske poeten Bengt Bergs och bildkonstnären Mona Nylins planerade sommarutställning Tidens ting och tankar i Värmlands läns museum blir det Margot Wallström och jag väntar på. Men det skulle vara regel inte undantag att låta utomstående kreativa personer lunka runt i magasin och arkiv, se och vrida på föremålen, studera fotografier och skriftliga dokument och sen göra utställningar utifrån erfarenheter, kunskaper och drivkrafter som är annorlunda än de akademiskt drillade arkeologernas, etnologernas och konsthistorikernas. Intendenternas tolkningsmonopol på det som kallas det kollektiva minnet måste brytas. 
I Sverige finns en konstnärligt inriktad högskola för film, radio, tv och teater. När läggs ordet utställning till? När kommer 120-poängskurserna i utställningsmanus och utställningsregi?
Det är en konstnärlig handling att omvandla innehållet $\mathrm{i}$ ett medium (talet) till ett annat medium (utställningen). Ett manuskript mellan talet och utställningen blir ett tredje medium att behärska - och beakta. Vem beställer det? Vem skriver det? Hur ser ett bra utställningsmanus ut? Är manus nödvändigt? En vetenskaplig eller populärvetenskaplig text har sin egen läsart och öppnar sig kanske inte tillräckligt för bildfantasin. ${ }^{13}$ Vore det bättre om någon intressant författare skrev hela manuset (och inte bara tillfogade utställningstexter i slutskedet)? Men då kanske det blir konflikter mellan två konstnärssjälar: författarens och bildkonstnärens? Vilka nya roller väntar museipersonalen om utställningen blir en konstform? Kommer utställningsproducentens arbete att likna en teaterregissörs? Det finns treårig regissörsutbildning i Sverige. Finns det konstnärlig utbildning för utställningsproducenter någonstans i världen?

Jag har i annat sammanhang ${ }^{14}$ presenterat idén om ett sommaruniversitet för utställ- ningsmakare: en fri men laddad mötesplats, där bildkonstnärer, författare, forskare, musiker och andra konstnärligt verksamma människor möter museifolk i kritiska diskussioner runt museiutställningens möjliga skepnader i framtiden. En sådan miljö skulle kunna vara inledningen till en mer systematisk utbildning av utställningsproducenter på hög akademisk-konstnärlig nivå.

Vad passar bättre än att avsluta med att citera en gammal motståndsman, som just har blivit tillgänglig på svenska:

Hellre en nybadad syndare än trenne rättfärdiga med fotsvett! Man har predikat $\mathrm{i}$ öknen så länge att man till slut är benägen att belöna sig själv med en rätt att värdera människor och ting estetiskt. Även vid livets taffel är en gäst som stoppar kniven i fickan ofta trevligare än en som stoppar den i munnen, och jag har omvänt aldrig tyckt bättre om en bordsgranne som spottat $\mathrm{i}$ min soppa för att han sagt sig vara 'en anständig människa'. Även om den stig som sökare efter mänsklig fullkomlighet har vandrat ständigt delar sig i nya vägskäl mellan ofull- 
komligheter, så har jag i valet mellan form utan innehåll eller innehåll utan form oftast stannat för det estetiska alternativet. ${ }^{15}$

Särskilt sista meningen måste jag opponera mig mot. Så erinrar jag mig konstnären och psykoanalytikern Rollo Mays tes: utan form inget innehåll ${ }^{16}$ och läser än en gång genom citatet.

\section{NOTER}

1. Ludwig Wittgenstein, Särskilda anmärkningar, Thales 1992. Sidorna 76 och 9.

2. Teaterscenografi i museer är alltför vanligt. De spatiala problem som tolkningen av en teaterpjäs ställer på scengolvet är ändå av annan karaktär än de kroppsliga utmaningar som utställningsrummet kan ge. Att - som museerna - göra sina besökare till publik istället för medspelare visar hur lite man är beredd att experimentera med utställningsmediet.

3. I Historiska museets djärva och innovativa bidrag till storutställningen Den svenska historien klagade de medverkande konstnärerna,som jag intervjuat, inte på brist på frihet utan på avsaknaden av motstånd.

4. Marshall McLuhan, Media. Människans utbyggnader. PAN/ Norstedts1967, sid 8.

5. Särskilda anmärkningar, sid 46.

6. Britta Lundgren: Kön, etnologi, museiverksambet. Det dolda budskapet. Seminarierapport. Arbetets museum och Riksutställningar 1993, sid 47.

7. Det encyklopediska tänkandet lämnar museitjänstemännen ingen ro. Även museer som har på programmet att utveckla utställningsmediet får onödiga återfall. Jag tänker på Kulturens Bokkulturen i Lund, Arbete och kärlek i Arbetets museum i Norrköping och stora delar av den nya basutställningen i Länsmuseet Murberget i Härnösand, alla från 1994-95. När föremålen ställs i den snabba upplysningens tjänst berövas de både form och funktion. De får inte spela ut sin sinnlighet; i stället för att berika varann i ett konfliktladdat spel naglas deras betydelse fast genom förklarande texter.

8. Thomas Tidholm, trafiken och tabletterna, ur diktsamlingen Notiser. Wahlström och Widstrand 1994.

9. Guldrummet på Historiska museet är ett bra exempel på hur en utställning blir offer för den museala narcissismen. Hade den lancerats som ett skottsäkert studiemagasin, skulle jag inte ha något att invända. Vackrare, bätttre belysta och överskådligare exponerade kan föremål inte bli. Men av en utställning måste man kräva mer, ett påstående, en komplikationsmedvetenhet, en provocerande diskussion som finnas uttalad i sättet att välja och kombinera föremålen och som gör sig påmind var än man befinner sig i utställningsrummet.

10. Uppmärksam på fotografiets bildmanipulerande förmåga och utnyttjande en alltmer förfinad reproduktionsteknik började författaren André Malraux skapa underbara imaginära konstmuseer redan för nästan ett halvsekel sedan. Idag översvämmas bokmarknaden av imaginära museer som friare och personligare än de reellt existerande skildrar världens, djurens och människornas utveckling. Men det behövs en ny och penningstarkare informationsteknologi än boktryckarkonsten för att museerna skall börja ifrågasätta sin estetiska eftersläpning och, förhoppningsvis, göra något åt den.

11. Informationsteknologi för museer. Konferensprogram, Uppsala universitet och Kurssekretariat 1995.

12. Intervju med Margot Wallström, Dagens Nyheter, 2.111995.

13. Det hävdar Gunilla Lundahl, idégivare och ansvarig för innehållet i utställningen Himla skönt. Vad är egentligen vackert? och kan förklara varför hon föredrar att tala sig fram till innehål- 
EVA PERSSON

100 let-formen i stället för att levera ett skrivet manus. Se: Eva Persson, Utställningsform.

Carlssons bokförlag 1993, sid $132 \mathrm{ff}$

14. Sommaruniversitet for utstälningsmakare.

Projektbeskrivning. Bidragsansökan till Stiftelsen framtidens kultur. 1995.

15. Karl Kraus, I denna stora tid. Texter ur Die

Fackel. Symposion 1995, sid 5.

16. Rollo May, Modet att skapa. Bonniers 1984.
Eva Persson var 1967-89 utställningsproducent vid Riksutställningar, Stockholm, 1989-93 konstnärlig ledare och producent vid Arbetets museum, Norrköping. Hon är f.n. frilansande utställningsproducent. Adr: Brännkyrkagatan 113, S-11728 Stockholm. Tellfax: +46-8-6685246

\section{SUMMARY}

Rather a newly bathed sinner than three

righteous ones with sweaty feet

The author states that in all her writings, lectures and seminars in recent years, she has returned again and again to the same basic issue: the nature of the museum exhibition as means of communication for the various messages and meanings inherent in the objects (cf 'Nordisk Museologi' 1995:1, p. 51-52). She is finally convinced that the exhibition must be considered an artistic medium and that it is only when an artist has interpreted the theme and the objects available for the exhibition that a meaningful contemporary communication can be arrived at. Quoting the present Minister of Culture, Mrs Margot Wallström, resident in Karlstad, who said that she would like to be «touched, seduced, disgusted, shocked" when visiting a museum, the author hopes that both the Minister and herself will be satisfied by an exhibition project now underway in the museum in Karlstad, where a poet and an artist have been invited to use all the holding resources of the museum to express themselves. She argues for the introduction of a qualified training for communicators in museum. 